\title{
Electrochemical Determination of Ascorbic Acid in Pharmaceutical Tablets using Carbon Paste Electrode
}

\author{
Zelalem Bitew and Meareg Amare* \\ Department of Chemistry, Bahir Dar University, Bahir Dar, Ethiopia
}

Submission: July 08, 2019; Published: August 30, 2019

"Corresponding author: Meareg Amare, Department of Chemistry, Bahir Dar University, Bahir Dar, Ethiopia

\begin{abstract}
Cyclic voltammetry was used to study the electrochemical behavior of ascorbic acid at carbon paste electrode. Ascorbic acid showed an irreversible oxidation peak at about $+470 \mathrm{mV}$. While the observed peak potential shift with $\mathrm{pH}$ in the range 0.5 to 6.0 indicated the participation of protons during the oxidation of ascorbic acid, the peak potential shift with scan rate in the range $10-300 \mathrm{mV} / \mathrm{s}$ confirmed the irreversibility of the oxidation reaction. Under optimized method and solution parameters, an excellent linear dependence of the oxidative peak current on concentration of ascorbic acid was observed in the range 10-100 $\mu \mathrm{M}$ with limits of detection (LOD) and quantification (LOQ) of 1.76 and 5.86 $\mu \mathrm{M}$, respectively. Detection of 93.33 to $97.58 \%$ of the expected ascorbic acid content in two local tablet formulations analyzed using the method confirmed the accuracy of the method. Recovery results in the range $91.65-91.83 \%$ for spiked standard ascorbic acid in pharmaceutical tablets further confirmed the potential applicability of the developed method for the determination of ascorbic acid in real samples.
\end{abstract}

Keywords: Ascorbic acid; Square wave voltammetry; Carbon Paste Electrode; Phosphate Buffer Solution; Pharmaceutical Tablets.

\section{Introduction}

Ascorbic acid, a water-soluble vitamin (Vitamin C), is important in forming collagen, a protein that gives structure to bones, muscles and blood vessels. It is the most common ubiquitous electroactive vitamins ever discovered. Ascorbic acid plays a paramount role as an antioxidant and free radical scavenger [1,2] and hence is a vital component in human diet with the highest concentrations in animal organs like liver, leukocytes, and anterior pituitary [3]. It is widely used in the treatment of certain diseases including scurvy, common cold, anemia, hemorrhagic disorders, wound healing as well as infertility $[4,5]$.

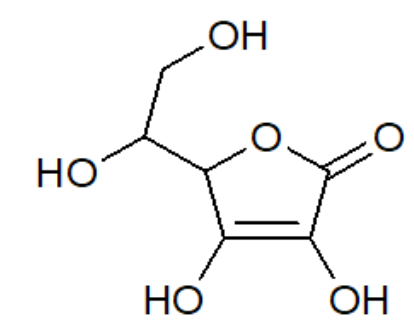

Scheme 1: The chemical structure of ascorbic acid.
Ascorbic acid (AA) known for its reductive properties is used as an antioxidant agent in foods and drinks, for therapeutic purposes and biological metabolism [6-8]. The human body cannot produce ascorbic acid, and so it must be obtained entirely through one's diet. Therefore, humans depend on exogenous sources of the vitamin which include fruits and vegetables as well as food supplements and pharmaceutical preparations [5]. The physicochemical and biochemical actions of vitamin C (scheme 1) are accounted for its action as an electron donor [9-11].

The amount of vitamin $\mathrm{C}$ required in a healthy diet varies with age and gender. According to Natural Health Product Monograph, children ages 1-3 require $15 \mathrm{mg} /$ day, adult females $75 \mathrm{mg} /$ day, and adult males need $90 \mathrm{mg} /$ day [12]. Although toxicity of AA is very rare, an intake of AA greater than 2,000 $\mathrm{mg} /$ day is not recommended for it may lead to stomach upset and diarrhea. A link between the high dose of AA in human body and increased risk of calcium oxalate kidney stones have also be reported although refutal studies are also reported $[12,13]$.

Titration [5], chromatography [14], fluorimetry [15], and spectrophotometry [16] are among the analytical methods commonly reported for determination of AA in real samples 
including pharmaceutical formulations, foods, fruits, and biological fluids. However, some of these methods are timeconsuming, while others are costly, require special training for operators of the equipment, or suffer from insufficient sensitivity or selectivity $[14,17]$.

On the other hand, recently developed electrochemical methods are more promising because they possess quick response times, low cost, simplicity of instrumentation, high sensitivity, and the possibility of miniaturization $[18,19]$. Considerable efforts have been made on the development of electrochemical methods for determination of AA in pharmaceutical formulations using $\mathrm{Pt}$ electrode [2], aluminum modified with nickel hexacyanoferrate film [6], glassy carbon electrode [19], and Bi203 /Glassy carbon electrode [20]. Although the reported electrochemical methods are sensitive with low detection limit, most of them have used expensive electrodes/modifiers. Thus, the development of simpler, cost effective, and sensitive method is needed for the determination of ascorbic acid in pharmaceutical formulations. In this study, square wave voltammetry determination of ascorbic acid in tablet samples using carbon paste electrode, which is the simplest and cheapest electrode material, is presented.

\section{Material and Methods}

\section{Chemicals and Apparatus}

Ascorbic acid (Blulux chemicals Ltd., India), graphite powder (BDH-Laboratory supplies Poole, England), Vitamin C tablets of two Ethiopian brands (EPHARM, and APF), paraffin oil (Abron Chemicals), disodium hydrogen phosphate, sodium dihydrogen phosphate, $\mathrm{NaOH}$, and $\mathrm{HCl}$ all (Blulux laboratories (p), Ltd) were used. Distilled water was used throughout the work.

A BAS 100B electrochemical analyzer [bioanalytical systems (BAS), USA] with carbon paste electrode as working electrode, platinum coil wire as auxiliary electrode and $\mathrm{Ag} / \mathrm{AgCl}$ as reference electrode was used. A Jenway model $3310 \mathrm{pH}$ meter and electronic balance (Denver instrument) were used for measuring the $\mathrm{pH}$ of the buffer solutions and mass of chemicals, respectively.

\section{Procedure}

\section{Preparation of Standard Solution}

Phosphate buffer solutions (PBS) in the $\mathrm{pH}$ range 0.5-6.0 were prepared from a mixture of $0.1 \mathrm{M} \mathrm{NaH2PO} 4$ and $0.1 \mathrm{M}$
Na2HPO4 in distilled water. $1 \mathrm{M} \mathrm{NaOH}$ and $1 \mathrm{M} \mathrm{HCl}$ solutions were used to adjust the $\mathrm{pH}$ of the buffer solutions. Stock solution of $0.01 \mathrm{M}$ ascorbic acid was prepared by dissolving $0.1761 \mathrm{~g}$ of ascorbic acid in $100 \mathrm{~mL}$ of the phosphate buffer solution ( $\mathrm{pH}$ 2) from which working standard solutions were prepared through serial dilution.

\section{Pharmaceutical Tablet Sample Preparation}

Vitamin C tablets of two Ethiopian brands, Ethiopian Pharmaceuticals Manufacturing (EPHARM) and Addis Pharmaceutical Factory (APF) were purchased from a local pharmacy. Five tablets (500 mg Ascorbic acid/tablet) from each brand were accurately weighed and finely powdered in a porcelain mortar. An adequate amount of this powder corresponding to a stock solution of $1 * 10-2$ mol L- 1 ascorbic acid was weighed, transferred into a $100 \mathrm{~mL}$ flask, and diluted to the mark with pH 2 PBS. After filtering with Watmann No 1 filter paper, tablet samples with 60,100 , and $300 \mu \mathrm{M}$ tablet sample.

\section{Preparation of Working Electrode}

Carbon paste electrode was prepared following the reported procedure [21]. Briefly, $1 \mathrm{~g}$ of carbon paste was prepared by mixing graphite powder with paraffin oil in a ratio of 70:30 $(\mathrm{w} / \mathrm{w})$, respectively. The mixture was homogenized with mortar and pestle for 30 minutes and allowed to rest for $24 \mathrm{hrs}$. The homogenized paste was packed into the tip of a plastic tube of a diameter about $3.5 \mathrm{~mm}$. A copper wire was inserted from the backside of the plastic tube to provide electrical contact. The surface of the electrode was smoothed manually against a smooth white paper until a shiny surface is emerged and the electrode was made ready for use.

\section{Electrochemical Procedure}

The electrochemical behavior of AA at CPE, effect of scan rate in the range of 10 to $300 \mathrm{mV} \mathrm{s}-1$ on the peak current and peak potential, and the influence of $\mathrm{pH}$ in the range $0.5-6.0$ on the peak potential and peak current of ascorbic acid were investigated using cyclic voltammetry in the potential window -100 to $1000 \mathrm{mV}$ and scan rate of $50 \mathrm{mV} \mathrm{s}-1$. Square wave voltammetry in the potential range -100 to $+1000 \mathrm{mV}$ was also used for quantitative determination of ascorbic acid. External standard addition method was employed for quantification of the ascorbic acid content in two brands of tablet formulation.

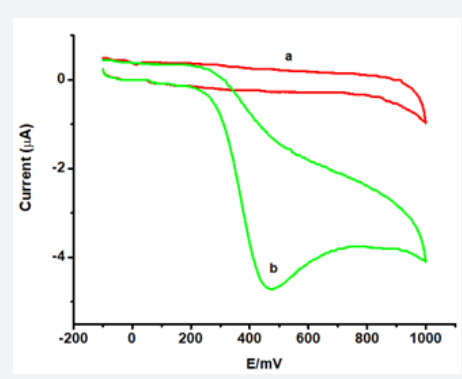

Figure 1: Cyclic voltammograms of CPE in pH 2 PBS containing (a) no AA (b) $0.5 \mathrm{mM} \mathrm{AA}$ at scan rate of $50 \mathrm{mV} \mathrm{s}^{-1}$. 


\section{Results and Discussion}

\section{Cyclic Voltammetric Investigation of Ascorbic Acid at CPE}

\section{Electrochemical Behavior of Ascorbic Acid at CPE}

Cyclic voltammetry was used to investigate the electrochemical behavior of AA at carbon paste electrode. Figure 1 presents the cyclic voltammograms of CPE in $\mathrm{pH} 2 \mathrm{PBS}$ containing (a) no AA and (b) $0.5 \mathrm{mM}$ AA. While no peak was observed in the absence of AA (curve a of Figure 1), appearance of an intensive peak centered at about $+470 \mathrm{mV}$ in the oxidative scan direction without a peak in the reductive scan direction implied an irreversible oxidation of AA at carbon paste electrode.

\section{Effect of Scan Rate}

Figure 2 describes the cyclic voltammograms of $0.5 \mathrm{mM} \mathrm{AA}$ in $\mathrm{pH} 2$ at the scan rate range of 10 to $300 \mathrm{mV} / \mathrm{s}$. As can be seen from the figure, the increase in anodic peak current (Ipa) with scan rate accompanied by peak potential shift in the positive direction confirmed the irreversibility of the oxidation reaction of AA.

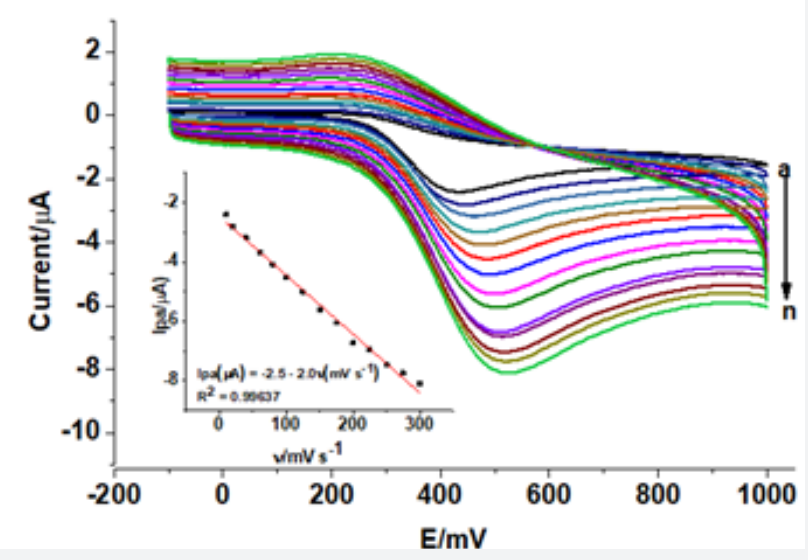

Figure 2: Cyclic voltammograms of pH 2 PBS containing $0.5 \mathrm{mM}$ AA at CPE at various scan rates (a-n: 10, 20, 40, 60, 80, 100, 125, 150, 175, 200, 225, 250, 275, and $300 \mathrm{mV} / \mathrm{s}$, respectively). Inset: Plot of peak current versus scan rate.

In order to investigate whether the oxidation process of ascorbic acid at CPE is predominantly diffusion controlled or surface confined process, the dependence of peak current on the scan rate and square root of scan rate was compared. A better correlation coefficient for the dependence of peak current on the scan rate $(R=0.99637)$ (Inset of Figure 2 ) than on the square root of scan rate $(R=0.99105)$ (figure not shown) indicated that the oxidation of AA at CPE is predominantly governed by surface-adsorption [22].

\section{Effect of $\mathrm{pH}$}

The effect of $\mathrm{pH}$ on the oxidation peak current and peak potential of AA at CPE was studied in the $\mathrm{pH}$ range 0.5-6.0. The cyclic voltammograms of $0.5 \mathrm{mM}$ of AA in PBS of various $\mathrm{pH}$ are shown in Figure 3. As can observed from Fig. 4a, the anodic peak current increased sharply from $\mathrm{pH} 0.5$ to 2 which then gradually decreased at $\mathrm{pH}$ higher than 2 . Thus, $\mathrm{pH} 2$ was selected as the optimum $\mathrm{pH}$ of the buffer solution in the subsequent experiments which agrees with previously reported works [22].

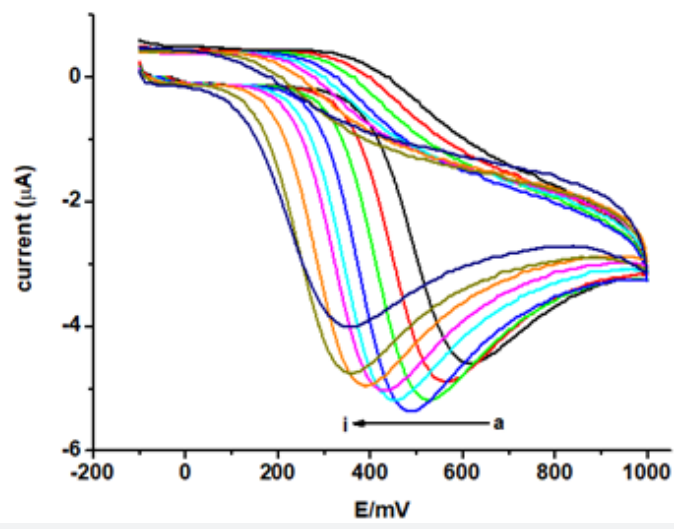

Figure 3: Cyclic voltammograms of $0.5 \mathrm{mM}$ AA in PBS of different $\mathrm{pH}$ values (a-i: 0.5, 1.0, 1.5, 2.0, 2.5, 3.0, 4.0, 5.0, and 6.0, respectively) at CPE. Scan rate: $50 \mathrm{mV} \mathrm{s}^{-1}$ 
The influence of $\mathrm{pH}$ on the oxidative peak potential of ascorbic acid was also examined. The oxidation peak potential shift in the negative potential direction with increase of $\mathrm{pH}$ indicates participation of protons during oxidation of AA at CPE (Figure 4). As can be observed from the figure, the potential shift showed linear dependence with the $\mathrm{pH}$ in the range 0.5 to 4.0 with a slope of $0.063 \mathrm{~V} / \mathrm{pH}$ indicating that the number of protons and electrons taking part in the electrode reaction were in a 1:1 ratio [23]. Hence, a reaction mechanism (scheme 2) was proposed for the oxidation of ascorbic acid at carbon paste electrode which agrees with previous reports [24].

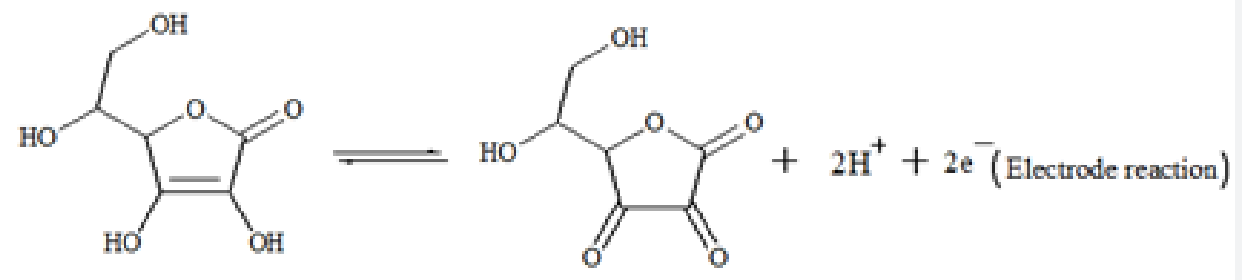

Scheme 2: The proposed oxidation mechanism of ascorbic acid at CPE.

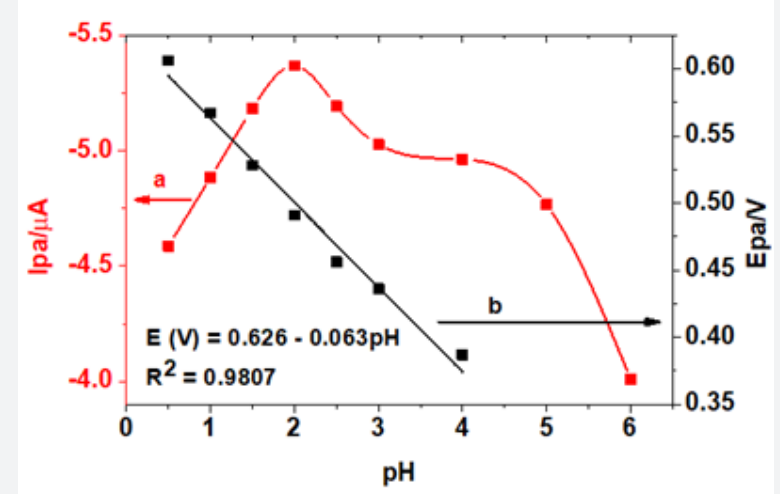

Figure 4: Plot of (a) oxidative peak current versus $\mathrm{pH}$, and (b) peak potential as a function of pH for $0.5 \mathrm{mM}$ AA in PBS solution at CPE. Scan rate: $50 \mathrm{mV} / \mathrm{s}$.

\section{Square Wave Voltammetric Investigation}

Square wave voltammetry, which is one of the most sensitive voltammetric techniques, was used for the quantitative determination of ascorbic acid. The electrochemical oxidation of ascorbic acid at carbon paste electrode was studied by square wave voltammetry in the potential range from -100 to $1000 \mathrm{mV}$. Figure 5 represents the square wave voltammograms of CPE in pH 2 PBS in the absence (a) and presence (b) of $0.5 \mathrm{mM} \mathrm{AA}$. The oxidative peak centered at about $+410 \mathrm{mV}$ in the presence of AA (curve b) while no peak in the absence of AA (curve a) was assigned for oxidation of AA.

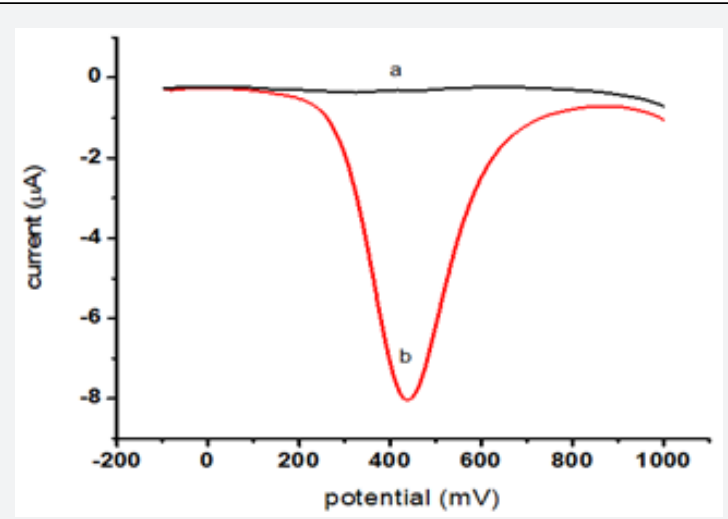

Figure 5: Square wave voltammograms of $\mathrm{CPE}$ in $\mathrm{pH} 2 \mathrm{PBS}$ (a) containing no AA and (b) $0.5 \mathrm{mM}$ AA. 


\section{Optimization of Method Parameters}

The effects of the square wave parameters frequency, amplitude and step potential, and accumulation parameters (Eacc and tacc) on the oxidative peak current of AA at CPE were investigated. As can be seen from the Inset of Figure 6, the magnitude of the peak current increased with increasing the square wave frequency. However, the peak current increment was accompanied by peak broadening and peak potential shift in the positive direction besides the peak current instability which affected the reproducibility of the measurement. As a compromise between the increased peak current and accompanied poor current reproducibility, frequency of $25 \mathrm{~Hz}$ was chosen as the optimum value in the subsequent experiments. Figure 7 demonstrates the effect of the amplitude on the oxidative peak current of AA at CPE. As expected, the peak current increased linearly with amplitude. However, the peak width also increased with square wave amplitude.

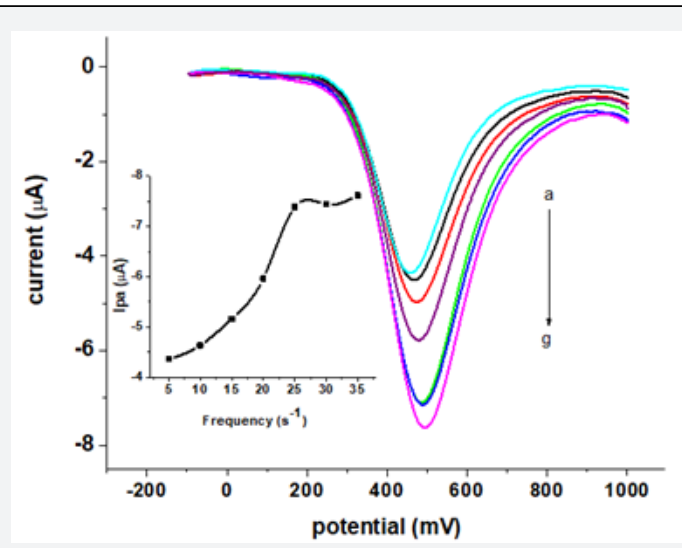

Figure 6: Square wave voltammograms of CPE in pH 2 PBS containing $0.5 \mathrm{mM} \mathrm{AA}$ at various frequencies (a-g: 5, 10, 15, 20, 25, 30, and 35 Hz, respectively). Inset: Plot of anodic peak current as a function of square wave voltammetric frequencies.

The effect of square wave amplitude on peak current is shown (Figure 7). Upon increasing the square wave amplitude, a linear increase in the peak current was observed accompanied by peak broadening when the amplitude was greater than $50 \mathrm{mV}$. Thus, $50 \mathrm{mV}$ was chosen as the optimum square wave amplitude which is a compromise between the peak height and the peak shape. The effect of square wave step potential on the peak current response of CPE for ascorbic acid was studied by varying the step potential from $2 \mathrm{mV}$ to $22 \mathrm{mV}$ (Figure 8). Hence, as a compromise between the peak current enhancement with increasing step potential (Inset of Fig. 8) accompanied by peak broadening, a step potential of $14 \mathrm{mV}$ was chosen as the optimum square wave step potential for further work.

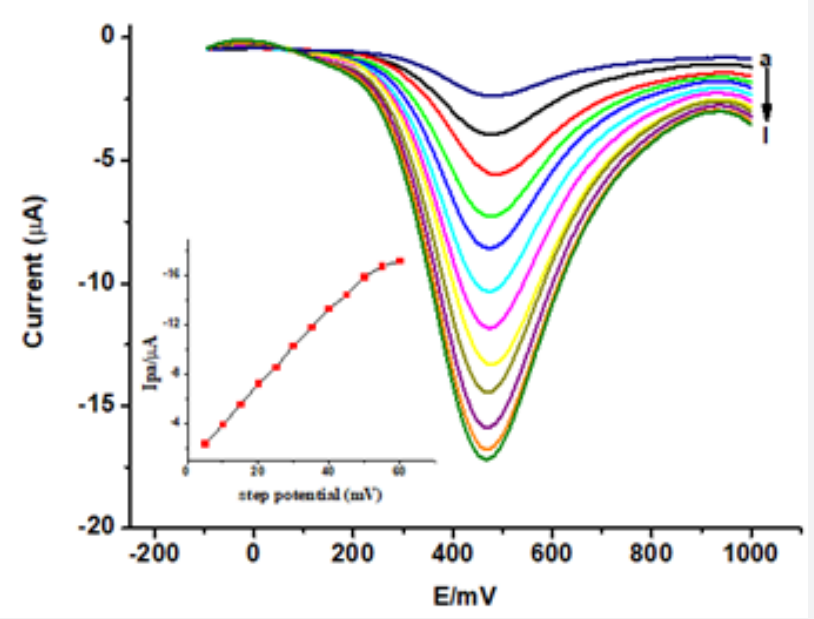

Figure 7: Square wave voltammograms of $0.5 \mathrm{mM} \mathrm{AA}$ in pH 2 PBS at CPE at different amplitudes (a-1: 5, 10, 15, 20, 25, 30, 35, 40, 45, 50, 55, and $60 \mathrm{mV}$, respectively). Inset: Plot of anodic peak current as a function of square wave amplitude of CPE in $0.5 \mathrm{mM} A A$ at various amplitudes. 


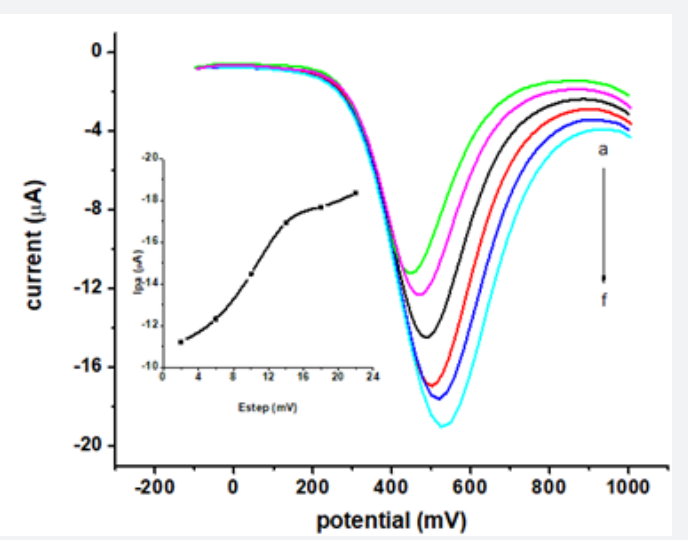

Figure 8: Square wave voltammograms of $0.5 \mathrm{mM}$ AA in pH 2 PBS at CPE at different step potentials (a-f: 2, 6, 10, 14, 18, and $22 \mathrm{mV}$, respectively). Inset: Plot of anodic peak current against the step potential.

Since the oxidation of ascorbic acid at CPE is governed predominantly by surface confined kinetics, the effects of accumulation time and accumulation potential were investigated, by varying one of them and maintaining the other constant. Figure 9a shows the effect of accumulation potential (Eacc) on the square wave peak current for $0.5 \mathrm{mM}$ AA over the range of 300-600 mV. As can be shown from the figure, the peak current increased with increasing the accumulation potential from up to $350 \mathrm{mV}$.

A peak current decrease was observed at accumulation potentials higher negative than $350 \mathrm{mV}$ and hence, a preconcentration potential of $350 \mathrm{mV}$ was taken as the optimum accumulation potential throughout the present work. Figure $9 \mathrm{~b}$ presents the effect of accumulation time on the oxidative peak current of $0.5 \mathrm{mM}$ AA at constant accumulation potential of 350 $\mathrm{mV}$. As can be seen from the figure, the peak current increased with the increase in accumulation time up to $20 \mathrm{~s}$ and then almost leveled off. The increase of peak current with increase in accumulation time indicated that AA can be accumulated at the surface of the CPE. The leveling off peak current after $20 \mathrm{~s}$ could be ascribed to the saturation of the surface of the electrode. So, the accumulation time of $20 \mathrm{~s}$ was selected as an optimum accumulation time for this work (Figure 9) (Table 1).
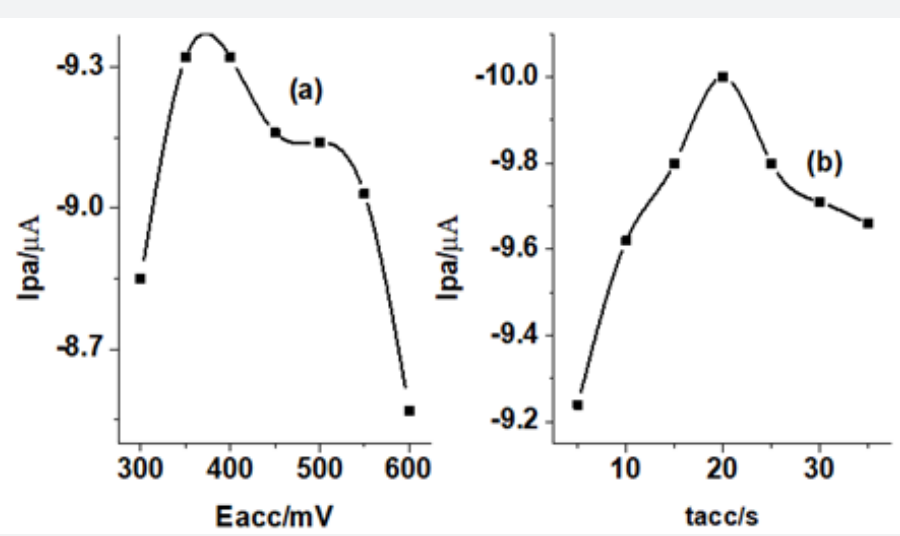

Figure 9: Plot of oxidative peak current of $0.5 \mathrm{mM}$ AA at CPE versus (a) various accumulation potentials, and (b) accumulation time..

Table 1: Summary of optimized solution and method parameters.

\begin{tabular}{|c|c|}
\hline Parameters & Optimized Values \\
\hline pH of the buffer solution & 2 \\
\hline Square wave frequency $(\mathrm{Hz})$ & 25 \\
\hline Square wave amplitude $(\mathrm{mV})$ & 50 \\
\hline Square wave step potential (mV) & 14 \\
\hline Accumulation potential $(\mathrm{mV})$ & 350 \\
\hline Accumulation time $(\mathrm{sec})$ & 20 \\
\hline
\end{tabular}




\section{Organic and Medicinal Chemistry International Journal}

Under the optimum experimental conditions, the dependence of square wave voltammetric oxidative peak current on the concentration of AA and inherited sensitivity of the method was investigated in the range $1 * 10-5-6 * 10-4$. While Figure 10 presents the square wave voltammograms of various concentrations of AA in $\mathrm{pH} 2 \mathrm{PBS}$ at $\mathrm{CPE}$, Inset of Fig. 10 shows the linear dependence of the oxidative peak current on concentration of $\mathrm{AA}$ in the studied range with regression equation, and correlation coefficient (R2)) of Ipa $(\mu A)=0.1343$ - 0.0442 C $(\mu \mathrm{M})$, and 0.99978 , respectively. The corresponding method limit of detection (LOD $=3 \mathrm{~s} / \mathrm{m}$ ) and limit of quantification $(\mathrm{LOQ}=10 \mathrm{~s} / \mathrm{m})$ were calculated to be $1.76 * 10-6$ and $5.86 * 10-6$, respectively where $\mathrm{s}$ is the mean blank standard deviation for $\mathrm{n}$ $=8$ and $\mathrm{m}$ is the slope of the regression equation.

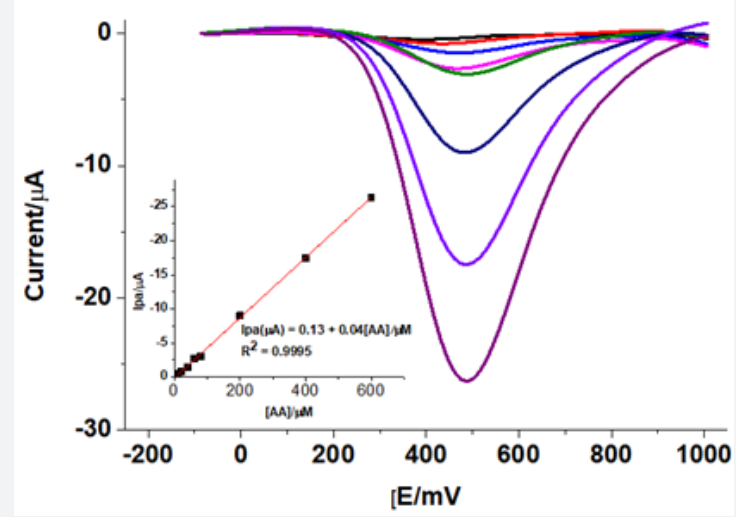

Figure 10: Corrected for background square wave voltammograms of $\mathrm{CPE}$ in $\mathrm{pH} 2 \mathrm{PBS}$ containing various concentrations of AA (a-h: 10, 20, 40, $60,80,200,400,600 \mu \mathrm{M}$, respectively). Experimental conditions: frequency $25 \mathrm{~Hz}$, amplitude $50 \mathrm{mV}$, step potential $14 \mathrm{mV}$, Eacc $350 \mathrm{mV}$, tacc 20 s. Inset: Plot of oxidative peak current versus concentration of AA.

The performance of the developed method for the detection of AA was compared with other reported methods. The developed method using CPE, which is the cheapest carbon-based electrode material, showed a comparable LOD and hence sensitivity with other reported works which have used expensive electrode materials (Table 2).

Table 2: Comparison between the developed method and other reported methods.

\begin{tabular}{|c|c|c|c|c|}
\hline Electrode & Method & Linear Range (M) & LoD (M) & Ref. \\
\hline $\mathrm{Pt}$ & $\mathrm{DPV}$ & $3.110^{-4}-210^{-2}$ & $8.7 * 10^{-5}$ & {$[2]$} \\
\hline $\mathrm{Bi}_{2} \mathrm{O}_{3} / \mathrm{GCE}$ & $\mathrm{CV}$ & $5 \times 10^{-4}-510^{-3}$ & $8.1 * 10^{-6}$ & {$[22]$} \\
\hline $\mathrm{MWCNT} / \mathrm{TTAB} / \mathrm{GCE}$ & $\mathrm{DPV}$ & $510^{-7}-1.710^{-4}$ & $1.1 * 10^{-7}$ & {$[18]$} \\
\hline $\mathrm{CPE}$ & $\mathrm{SWV}$ & $110^{-5}-610^{-4}$ & $1.76 * 10^{-6}$ & This work \\
\hline
\end{tabular}

\section{Real Sample Analysis}

The applicability of carbon paste electrode for determination of AA was demonstrated by applying it to determine the AA content in some pharmaceutical preparations. In this work, two brands of vitamin $\mathrm{C}$ tablets (APF, and EPHARM) prepared following the procedure described under the experimental section were selected for the analysis of AA. Finally, 70, 100, and $400 \mu \mathrm{M}$ tablet sample solutions were prepared from the corresponding stock solution. Square wave voltammograms were recorded (Figure 11) following the outlined voltammetric procedure and optimized conditions as described earlier. Mean of triplicate measurements was taken for the determination of AA in these samples.
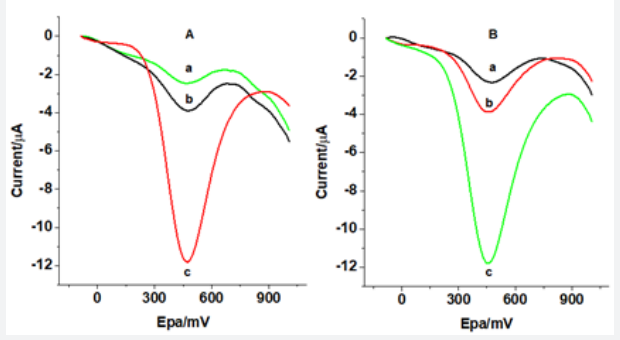

Figure 11: Square wave voltammograms of vitamin $C$ tablets (A) APF, and (B) EPHARM brands with various theoretical concentrations (a-c: 60, 90, $234 \mu \mathrm{M}$, respectively) in $\mathrm{pH} 2$ PBS at CPE. Conditions: optimized SWV and accumulation parameters. 
The amount of AA found in the different concentrations of the two brands of tablets is summarized in Table 3. For EPHARM and APF tablets the prescribed levels of AA were $500 \mathrm{mg}$ per tablet whereas the amount of AA detected relative to the level were about $91.105 \%$ and $91.173 \%$, respectively. Detected values lower than prescribed value may be due to the oxidation of AA during preparation or sort of degradation during storage or may contain lower levels of AA in tablets.

Table 3: Amount of AA detected in two brands of tablets in using the developed method.

\begin{tabular}{|c|c|c|c|c|c|}
\hline Tablets/ $\mu \mathrm{M}$ & Expected $(\mu \mathrm{M})$ & \multicolumn{2}{|c|}{ Detected $^{*}(\mu \mathrm{M})(\mathrm{mg} /$ tablet $)$} & Prescribed value (mg/tablet) & Measured \% \\
\hline \multirow{3}{*}{$\mathrm{APF}$} & 60 & & & & \\
\hline & 100 & 93.75 & 468.75 & 500 & 93.75 \\
\hline & 300 & 292.5 & 487.5 & 500 & 97.5 \\
\hline \multirow{3}{*}{ EPHARM } & 60 & 56 & 466.65 & 500 & 93.33 \\
\hline & 100 & 94.5 & 472.5 & 500 & 94.5 \\
\hline & 300 & 292.75 & 487.9 & 500 & 97.58 \\
\hline
\end{tabular}

To further evaluate the performance of the method, the recovery $100 \mu \mathrm{M}$ standard AA from spiked tablet samples of the two brands each of $100 \mu \mathrm{M}$ AA as per to the label. As can be seen from Table 4, excellent recovery results in the range of $91.65 \%$ to $91.83 \%$ with low RSD in the range $0.04-1.14$ confirmed the potential applicability of the developed method for AA analysis in real samples.

Table 4: Percentage recovery of spiked AA from pharmaceutical tablet samples.

\begin{tabular}{|c|c|c|c|c|c|}
\hline Tablet brand & Initial $[\mathbf{A A}] \mathbf{(} \boldsymbol{\mu M})$ & Spiked $[\mathbf{A A}](\boldsymbol{\mu M})$ & Found $[\mathrm{AA}](\boldsymbol{\mu M})$ & Recovery (\%) & RSD (\%) \\
\hline APF & 100 & 100 & 91.65 & 91.65 & 0.04 \\
\hline EPHARM & 100 & 100 & 91.83 & 91.83 & 1.14 \\
\hline
\end{tabular}

\section{Conclusion}

Cyclic voltammetric investigation of Ascorbic acid at CPE showed that the oxidation of Ascorbic acid over the studied range of scan rates is irreversible. While peak potential shift with the scan rate confirmed the irreversibility of the reaction, peak potential shift with $\mathrm{pH}$ also indicated the involvement of protons in the oxidation process. The ease of preparation of the electrode in combination with the relatively low detection limit, better selectivity and sensitivity, very good recoveries relative to previously reported works which have used expensive electrodes illustrated the potential applicability of the developed method as an alternative method for the determination of Ascorbic acid in real samples like pharmaceutical formulations.

\section{References}

1. Yilmaz S, Sadikoglu M, Saglikoglu G, Yagmur S, Askin G (2008) Determination of ascorbic acid in tablet dosage forms and some fruit juices by DPV. International Journal of Electrochemical Science 3: 1534-1542.

2. Pisoschi A M, Pop A, Negulescu G P, Pisoschi A (2011) Determination of ascorbic acid content of some fruit juices and wine by voltammetry performed at Pt and carbon paste electrodes. Molecules 16(2): 13491365.

3. Ensafi A A, Taei M, Khayamian T, Arabzadeh A (2010) Highly selective determination of ascorbic acid, dopamine, and uric acid by differential pulse voltammetry using poly (sulfonazo III) modified glassy carbon electrode. Sensors and Actuators B: Chemical 147(1): 213-221.

4. Revanasiddappa H D, Veena M A (2008) Sensitive spectrophotometric methods for the determination of ascorbic acid. E-Journal of Chemistry 5(1): 10-15.

5. Okiei W , Ogunlesi M , Azeez L , Obakachi V , Osunsanmi M (2009) The voltammetric and titrimetric determination of ascorbic acid levels in tropical fruit samples. International Journal of Electrochemical Science 4: 276-287.

6. Pournaghi Azar M H , Razmi Nerbin H, Hafezi B (2002) Amperometric determination of ascorbic acid in real samples using an aluminum electrode, modified with nickel hexacyanoferrate films by simple electroless dipping method. Electroanalysis 14(3): 206-212.

7. Raoof J B , Ojani R, Beitollahi H (2007) Electrocatalytic determination of ascorbic acid at chemically modified carbon paste electrode with 2 , 7-bis (Ferrocenyl ethynyl) fluoren-9-one. Int J Electrochem 2: 534-548.

8. Salkić M , Keran H, Jašić, M (2009) Determination of L-ascorbic acid in pharmaceutical preparations using direct ultraviolet spectrophotometry. Agriculturae Conspectus Scientificus 74(3): 263268.

9. Padayatty S J , Katz A, Wang Y, Eck P, Kwon O, et al. (2003) Vitamin C as an antioxidant: Evaluation of its role in disease prevention. Journal of the American College of Nutrition 22(1): 18-24.

10. WHO, Vitamin and mineral requirements in human nutrition, ( $\left.2^{\text {nd }} e d n\right)$, World Health Organization and Food and Agriculture Organization of the United Nations, 2004? 130-139.

11. Beitollahi, H, Mohammadi S (2013) Voltammetric determination of ascorbic acid in the presence of acetaminophen and tryptophan using an improved carbon nanotube paste electrode. Chinese Journal of Catalysis 34(6): 1098-1104.

12. Esch J R , Friend J R, Kariuki J K (2010) Determination of the vitamin C content of conventionally and organically grown fruits by cyclic voltammetry. International Journal of Electrochemical Science 5: 14641474.

13. Kroner Z (2011) Vitamins and minerals, ABC-CLIO, LLC, Santa Barbara, California, 141-146.

14. Mitic S S, Kostic D A, Naskovic okic D C, Mitic N M (2011) Rapid and reliable HPLC method for the determination of vitamin $C$ in pharmaceutical samples. Tropical Journal of Pharmaceutical Research 10(1): 105-111. 
15. Eitenmiller R R, Landen W O, Ye L (2008) Vitamin analysis for the health and food sciences, ( $2^{\text {nd }}$ edn), CRC Press Taylor \& Francis Group, 231-240.

16. Tiwari K K (2010) A new spectrophotometric method for the determination of ascorbic acid using leuco malachite green. Journal of the Chinese Chemical Society 57: 105-110.

17. Gazdik Z , Zitka O , Petrlova J , Adam V , Zehnalek J, et al. (2008) Determination of vitamin $\mathrm{C}$ using high performance liquid chromatography coupled with electrochemical detection. Sensors 8(11): 7097-7101.

18. Ramrez Berriozabal M, Galicia L, Gutie rrez Granados S, Cortes J S Herrasti, P (2008) Selective electrochemical determination of uric acid in the presence of ascorbic acid using a carbon paste electrode modified with b-cyclodextrin. Electroanalysis 20(15): 1678-1683.

19. Motahary M , Ghoreishi S M , Behpour M, Golestaneh M (2010) Electrochemical determination of ascorbic acid at the surface of a graphite electrode modified with multi-walled carbon nanotubes/ tetradecyltrimethylammonium bromide. Journal of Applied Electrochemistry 40(4): 841-847.

DOI: 10.19080/OMCIJ.2019.08.555749
20. Zidan M , Tee T W , Abdullah A H , Zainal Z, Kheng G J (2011) Electrochemical oxidation of ascorbic acid mediated by $\mathrm{Bi} 203$ microparticles modified glassy carbon electrode. International Journal of Electrochemical Science 6(2): 289-300.

21. Tunay Z , Sahin I, Nakiboglu N (2011) Voltammetric determination of boron using cobalt pthalocyanine modified carbon paste electrode. International Journal of Electrochemical Science 6(12): 6628-6638.

22. Ngai K S , Tan W T , Zainal Z , Zawawi R M, Zidan M (2012) Electrochemical oxidation of ascorbic acid mediated by single-walled carbon nanotube/tungsten oxide nanoparticles modified glassy carbon electrode. International Journal of Electrochemical Science 7(5): 42104222.

23. Huang D Q, Chen C, Wu Y M , Zhang H , Sheng L Q, et al. (2012) The determination of dopamine using glassy carbon electrode pretreated by a simple electrochemical method. International Journal of Electrochemical Science 7(6): 5510-5520.

24. Erdurak Kiliç C S, Uslu B, Dogan B, Ozgen U, Ozkan S A, et al. (2006) Anodic voltammetric behavior of ascorbic acid and its selective determination in pharmaceutical dosage forms and some. Rosa species of Turkey 61(11): 1113-1120.

\section{Your next submission with Juniper Publishers will reach you the below assets}

- Quality Editorial service

- Swift Peer Review

- Reprints availability

- E-prints Service

- Manuscript Podcast for convenient understanding

- Global attainment for your research

- Manuscript accessibility in different formats

(Pdf, E-pub, Full Text, Audio)

- Unceasing customer service

Track the below URL for one-step submission https://juniperpublishers.com/online-submission.php 